ORIGINAL RESEARCH ARTICLE

\title{
Unpacking the Barriers to Reproductive Health Services in Ghana: HIV/STI Testing, Abortion and Contraception
}

\author{
Nandita Thatte*, Jeffrey B. Bingenheimer, Khadidiatou Ndiaye and Rajiv N. Rimal \\ The George Washington Milken School of Public Health, Washington DC, USA \\ *For Correspondence: Email: nthatte@gwmail.gwu.edu, Phone: +1-202-341-0756
}

\begin{abstract}
Youth report embarrassment, cost, and poor access as barriers to sexual and reproductive health (SRH) services. Interventions to address barriers like youth friendly services have yet to conclusively demonstrate impact on protective behaviours like condom or contraceptive use. SRH encompasses a range of services so we aimed to assess how perceived barriers differed depending on the service being sought between common services accessed by young people: HIV/STI testing, abortion, and contraception. 1203 Ghanaian youth were interviewed. Data was analysed to identify barriers by service type, demographics, and between high and low HIV prevalence communities. Being embarrassed or shy was the most commonly reported barrier across services. Overall being embarrassed or shy, fear of safety, fear of family finding out and cost were the most reported barriers across all services. Further analysis by service indicated that being embarrassed was a significantly greater barrier for HIV/STI testing and contraception when compared with abortion $(\mathrm{p}<0.001)$ and safety concerns and cost were significantly greater barriers for abortion and contraception compared with HIV/STI testing $(\mathrm{p}<0.001)$. Efforts to develop interventions that consider the service being sought may help address the range of barriers faced by youth with diverse SRH needs. (Afr J Reprod Health 2016; 20[2]: 5361).
\end{abstract}

Keywords: Barriers, HIV/AIDS/STIs, Abortion, Contraception, Ghana, Youth.

\section{Résumé}

L'embarras du rapport de la jeunesse, le coût et le manque d'accès comme des obstacles aux services de santé sexuelle et de la reproduction (SSR). Les interventions visant à surmonter les obstacles tels que les services adaptés à la jeunesse n'ont pas encore démontré de façon définitive leur impact sur les comportements de protection comme le préservatif ou l'utilisation des contraceptifs. Les SSR englobent une gamme de services que nous visons à évaluer dans quelle mesure les obstacles perçus sont diffèrents selon le type de service recherché entre les services communs accessibles par les jeunes: le dépistage du VIH, IST, l'avortement, et la contraception. 1203 jeunes Ghanéens ont été interrogés. Les données ont été analysées afin d'identifier les obstacles par type de service, la démographie, et entre les communautés qui ont des de prévalence élevée et faible du VIH/IST. Le fait d'être embarrassé constitue significativement un plus grand obstacle pour le dépistage du VIH / IST et la contraception par rapport à l'avortement $(\mathrm{p}<0,001)$. Les préoccupations de sécurité et les coûts constituaient beaucoup plus de grands obstacles pour l'avortement et à la contraception par rapport au dépistage du VIH / IST ( p <0,001). Les efforts pour élaborer des interventions qui considèrent le service recherché peuvent peut-être aider à surmonter les obstacles rencontrés par les jeunes qui ont une gamme de besoins relatifs au SSR. (Afr J Reprod Health 2016; 20[2]: 53-61).

Mots-clés: Obstacles, VIH / SIDA / IST, avortement, contraception, Ghana, jeunesse.

\section{Introduction}

Young people around the world face many sexual and reproductive health (SRH) risks. According to UNAIDS, $45 \%$ of new HIV infections occur among people ages $15-24^{1}$. In addition, there are 333 million new STIs each year, with the highest rates occurring among those 15-24 years old ${ }^{2}$. Unplanned pregnancy among young people often leads to unsafe abortion, which can result in severe complications and even death ${ }^{3}$. Unintended pregnancy, HIV/STI infections and unsafe abortion have been reported as the SRH issues of greatest concern to young people ${ }^{4}$. These issues are related as consistent condom use can help prevent HIV and other STIs, and use of contraceptives can help prevent unintended pregnancies, which can decrease risks associated with unsafe abortion. Despite the clear linkages between these preventive behaviours, practices are still low in West Africa. This is particularly significant given that the proportion of sexually 
active unmarried youth is highest in this region (18.8\% compared with 9.7\% in East and Southern Africa) $)^{5}$. Finally, Ghana, like other countries in the region, has an increasingly large youth population and the country is well positioned to capitalize on achieving the demographic dividend ${ }^{6}$. Fifty per cent of the population in Ghana less than 25 years old and $25 \%$ of the population less than 10 years old. Investing in education, job creation, and sexual and reproductive health of these young people can contribute to the economic growth and stability for future generations ${ }^{6,7}$.

Correct and consistent condom use among youth continues to be a challenge and condom use at last sex among 15-24 year olds is less than 50\% globally $^{8}$. In Ghana, condom use is even lower. Among sexually active adolescents aged 15-19, less than $20 \%$ of girls and $30 \%$ of boys reported using condoms at last sex ${ }^{9}$. HIV/STI testing is also low with fewer than 5\% of sexually active adolescents in Ghana reporting ever having an HIV test and even fewer seeking treatment for STIs ${ }^{10}$. Contraceptive prevalence among youth in Ghana is also low and almost half of both married (45.7\%) and unmarried (48.7\%) youth want to prevent pregnancy but are not using any form of modern contraception (including condoms). This contributes to making Ghana the country with the highest unmet need for contraception among youth in the world 5 .

A recent study in Ghana among urban adolescents found that $86 \%$ of boys who had made a girl pregnant and $74 \%$ of girls who had ever been pregnant, reported that the pregnancy was unintended. Of these, $57 \%$ of young men and 23\% of young women reported ending the pregnancy in abortion $^{11}$. In 2006 the Ghana Ministry of Health instituted new guidance to ensure that abortions be provided legally and safely to women in need. However only $4 \%$ of women seeking abortions were aware of these services and $45 \%$ of abortion services are still unsafe, making abortion the second most common cause of mortality among young women in Ghana ${ }^{12}$.

Numerous factors contribute to the low use of SRH services among youth in sub-Saharan African (SSA). Health systems barriers like chronic stock-outs of contraceptives, disrespectful staff, poor counselling, limited access to services and cost have all been reported ${ }^{10,13}$. Studies have shown significant provider bias in providing contraceptives, particularly to unmarried women or young people $\mathrm{e}^{10,14}$. In Senegal one study found providers offering contraceptives only if the client met certain age requirements irrespective of marital status (age 17 for the pill, 18 for the injectable and 20 for long acting methods $)^{15}$. Cost is another barrier, particularly for abortion and contraceptive services. In one study, young women reported paying up to $\$ 90 \mathrm{USD}$ for abortion services ${ }^{16}$ and in Uganda $35 \%$ of adolescents reported cost as a top barrier for contraceptives $^{10}$. In addition to health systems barriers, youth also face individual barriers to seeking services. Previous studies have reported embarrassment, shame and fear as key barriers to seeking SRH services $^{10}$. Youth also report perceived promiscuity or mistrust of partners as barriers to seeking contraception ${ }^{17}$. Lack of knowledge about services, partner dynamics and attitudes about sexual behaviour have also been reported as barriers among youth ${ }^{10,13,17}$.

Interventions to increase use of SRH services among young people have had mixed results. Youth -friendly services are those that aim to address some structural and service delivery barriers like extending hours to meet the schedules of young people or providing education and counselling materials catered to youth. However, the impact of these programs on service delivery is inconclusive $^{18,19}$. A systematic review assessing the impact of 'youth-friendly' interventions to increase use of health services found that interventions with linkages to other community networks like peer groups and schools had moderate effects on behaviours, but youth-friendly clinics or peer-to-peer education alone had no significant effect on increasing any protective sexual health behaviours ${ }^{18,20}$.

There has been significant documentation of barriers to SRH services among youth; however SRH comprises a range of services so more detailed characterization of these barriers may provide useful guidance for policies and programs. Behavioural attributions or the unique characteristics that encompass a behaviour such as privacy (i.e. condom use) or cost/benefit (i.e. contraception versus unsafe abortion $)^{21,22}$ may also 
drive perceptions and can be explored when barriers to services are analysed separately.

In addition to understanding how barriers to SRH services may vary depending on the service being sought, subgroups of youth may also perceive barriers differently. Adult studies have shown that differences exist in barriers to HIV testing/disclosure by gender. Men report fear of perceived unfaithfulness by their partners, whereas women report fear of abuse or economic constraints as reasons not to test or disclose HIV status $^{23}$. Other evidence suggests that young people in school are more likely to delay sexual debut and engage in more protective sexual behaviours $^{3,24,25}$. Barriers to accessing SRH services for out of school have been less studied and require additional research ${ }^{10}$.

In 2011, the World Health Organization identified improving access to contraceptives and other SRH services as one of the top priorities for improving adolescent health outcomes ${ }^{26}$. In addition, the Ghana Adolescent Reproductive Health Policy outlines the need to "increase the availability of and accessibility to adolescent reproductive health services, including family planning, management of STIs, HIV/AIDS, safe motherhood and counselling" 27 . Young people are a diverse group and efforts to understand how barriers might differ by demographic characteristics and depending on the service being sought can help inform programmatic interventions and areas for future research.

This paper will address the following questions:

1. What are the barriers to SRH services among youth in Ghana?

2. How do barriers differ by the service being sought?

3. How do barriers differ by demographics and the prevalence of HIV in the community

\section{Methods}

\section{Setting}

Data for the study were collected from two towns in the south-eastern part of Ghana: Agormanya and Juapong. Both towns are regional trading hubs with populations of about 13,000 people each. However, Agormanya has experienced a high HIV disease burden with a prevalence of $10.4 \%$, significantly higher than the national prevalence $(1.3 \%)^{28}$. In comparison, Juapong has an estimated HIV prevalence closer to the national average at around $2.8 \%{ }^{28}$.

\section{Study Design}

Data for this study come from the Gendered Social Context Study, a multi-year study (2010-2014) to assess factors associated with developing patterns of sexual and reproductive health attitudes among youth collected at three time periods 18 months apart. Health care seeking behaviours were not assessed. Two cohorts of youth were sampled in the original survey design: 1.) Boys and girls ages 13-14 years old and 2.) Boys and girls ages 18-19 years old. Details from the original study including sampling methodology and consent procedures have been reported elsewhere ${ }^{29}$. This paper presents a cross sectional analysis that uses data collected at the $2^{\text {nd }}$ time period. Of the total originally sampled at Time $1(n=1275), 1203$ were included in the current analysis reflecting a $94 \%$ response rate. Survey items included demographics, parent and peer influences, gender roles and attitudes, sexual and reproductive health knowledge, attitudes and behaviours, barriers to services, and risk perceptions for HIV and pregnancy outcomes. Questionnaires were administered by trained interviewers from university of Ghana. The institutional review boards from the same University of Ghana and the George Washington University in the United States approved the study.

\section{Measures}

The dependent variables were perceived barriers to HIV/STI testing, abortion, and contraceptive services. These were assessed by asking respondents, "What might make it difficult for a young person to get tested for HIV/AIDS or other STIs around here?" with similar questions for abortion and contraceptive services. Contraceptive services included both condoms and other methods. Respondents were asked to answer freely and survey administrators recorded all responses using a list of 19 possibilities: afraid family will find out, afraid friends will find out, afraid partner will find out, afraid others will find out, religious 
prohibition, embarrassed/shy, not knowing where to go, lack of transport, inconvenient days/hours, privacy not respected, not treated well by staff, costly/not able to pay, no same sex provider, not being allowed to go, afraid for safety, treatment doesn't work, don't know, and other. For questions where respondents reported "Other", survey administrators recorded the openended response. For analytic purposes, each response was subsequently coded as 0 or 1 and then summed to assess the percentage reported for each barrier. Respondents were able to report multiple barriers for each service. Independent variables included gender, community (high versus low HIV prevalence), school status (inschool versus out of school), and age group (younger 11-16 and older 17-24).

\section{Analysis}

Descriptive analyses provided summary statistics of participants and an overview of perceived barriers reported. Barriers that were reported by at least $10 \%$ of respondents for any of the three services being sought were included for the between group analyses. These included: "Afraid family would find out", "afraid friends would find out", "afraid others would find out", "religious prohibition", "being embarrassed/ shy", "cost"and "afraid for safety." McNemars test was used to test for consistency between how respondents reported barriers between the different services being sought. Comparisons were made between HIV/STI testing and contraception, contraception and abortion, and HIV/STI testing and abortion controlling for age group, community, school status and gender. In order to account for small sample sizes in some cells, Fisher's exact test was used to assess how barriers differed between the different demographic groups. STATA 12.0 statistical software (Stata Corporation, College Station, TX, USA) was used for the analysis. A p-value of less than 0.05 was considered statistically significant.

\section{Results}

A total of 1203 youth $(45.7 \%$ male, $54.3 \%$ female) were included in the sample (Table 1). Youth ranged in age from 11 to 24 years old.
Table 1: Basic Demographics of Sample by HIV Prevalence Community \% of Total Sample $(n=1203)$

\begin{tabular}{lll}
\hline & $\begin{array}{l}\text { Low } \\
\text { Prevalence } \\
\text { Community } \\
(\mathbf{n = 5 9 2 )}\end{array}$ & $\begin{array}{l}\text { High HIV } \\
\text { Prevalence } \\
\text { Communit } \\
\mathbf{y}(\mathbf{n}=\mathbf{6 1 1})\end{array}$ \\
\hline Gender & & \\
Boys & 22.2 & 23.4 \\
Girls & 26.9 & 27.3 \\
Age & & \\
$11-16$ & 27.8 & 25.1 \\
$17-24$ & 21.4 & 25.7 \\
School Status & & \\
In School & 39.0 & 34.9 \\
Out of School & 9.8 & $15.1^{* *}$ \\
Sexual Experience & & $18.4^{* *}$ \\
Ever Had Sex & 12.1 & \\
\hline
\end{tabular}

$* \mathrm{p}<0.05 ; * \mathrm{p}<0.001$

The majority $(69.5 \%)$ reported no prior sexual experience and were in school $(74.8 \%)$ at the time the survey was administered. Age and gender distributions were similar among youth in both the high and low HIV prevalence communities.

Table 2: Percent of Respondents Reporting Barriers to Accessing SRH Services \% of Total Sample (n=1203)

\begin{tabular}{|c|c|c|c|}
\hline & $\begin{array}{l}\text { HIV/STI } \\
\text { Testing } \\
(\%)\end{array}$ & $\begin{array}{l}\text { Abortion } \\
(\%)\end{array}$ & $\begin{array}{l}\text { Contra } \\
\text { ception } \\
(\%)\end{array}$ \\
\hline Embarrassed / Shy & $43.8^{*}$ & $29.1 *$ & $37.6^{*}$ \\
\hline Afraid family will find out & 15.2 & 17.3 & 7.7 \\
\hline $\begin{array}{l}\text { Afraid friends will find } \\
\text { out }\end{array}$ & $15.7 *$ & 10.9 & 5.2 \\
\hline Afraid others will find out & $18.9 *$ & 9.8 & 5.3 \\
\hline Fear of Safety/Death & 11.5 & $41.8 *$ & $16.8 *$ \\
\hline Religious prohibition & 0.5 & 11.1 & 3.1 \\
\hline Costly / Not able to pay & 6.6 & $20.1 *$ & $11.8 *$ \\
\hline $\begin{array}{l}\text { Afraid partner will find } \\
\text { out }\end{array}$ & 4.0 & 2.7 & 2.3 \\
\hline Not knowing where to go & 2.3 & 1.2 & 2.1 \\
\hline Privacy not respected & 2.4 & 0.8 & 1.9 \\
\hline Not treated well by staff & 0.9 & 1.9 & 0.9 \\
\hline Lack of transport & 0.7 & 0.3 & 0.4 \\
\hline Inconvenient days/hours & 0.6 & 0.3 & 0.4 \\
\hline No same sex provider & 2.7 & 0.1 & 0.1 \\
\hline Not being allowed to go & 0.1 & 0.7 & 0.3 \\
\hline Treatment doesn't work & 0.0 & 2.8 & 3.2 \\
\hline Fear of infertility & $\mathrm{n} / \mathrm{a}$ & 1.7 & 1.3 \\
\hline $\begin{array}{l}\text { Fear of Outcome (HIV } \\
\text { Positive) }\end{array}$ & 9.3 & $\mathrm{n} / \mathrm{a}$ & $\mathrm{n} / \mathrm{a}$ \\
\hline Fear of Side Effects & $\mathrm{n} / \mathrm{a}$ & $\mathrm{n} / \mathrm{a}$ & 4.5 \\
\hline Desire to Get Pregnant & $\mathrm{n} / \mathrm{a}$ & $\mathrm{n} / \mathrm{a}$ & 0.2 \\
\hline
\end{tabular}

*Top three commonly reported barrier for selected SRH services 
Table 3: Comparison Between Percentage of Respondents Reporting Key Perceived Barriers by SRH Service Using McNemars Test

\begin{tabular}{lllllll}
\hline Barriers & $\begin{array}{l}\text { HIV/STI } \\
\text { Test } \\
\text { (A) }\end{array}$ & $\begin{array}{l}\text { Abortion } \\
\text { (B) }\end{array}$ & $\begin{array}{l}\text { Contra- } \\
\text { ception } \\
\text { (C) }\end{array}$ & A versus B & B versus C & A versus C \\
\hline Afraid Family will find out & 15.2 & 17.3 & 7.7 & $0.028^{*}$ & $0.000^{* * *}$ & $0.000^{* *}$ \\
Afraid Friends will find out & 15.7 & 10.9 & 5.2 & $0.000^{* *}$ & $0.000^{* *}$ & $0.000^{* *}$ \\
Afraid Others will find out & 18.9 & 9.8 & 5.3 & $0.000^{* *}$ & $0.002^{*}$ & $0.000^{* *}$ \\
Religious Prohibition & 0.5 & 11.1 & 3.1 & $0.000^{* *}$ & $0.000^{* *}$ & $0.000^{* *}$ \\
Embarrassed/Shy & 43.8 & 29.1 & 37.6 & $0.000^{* *}$ & $0.000^{* *}$ & $0.000^{* *}$ \\
Cost & 6.6 & 20.0 & 11.8 & $0.000^{* *}$ & $0.000^{* *}$ & $0.000^{* *}$ \\
Afraid for Safety & 11.5 & 34.6 & 16.8 & $0.000^{* *}$ & $0.000^{* *}$ & 0.065 \\
\hline
\end{tabular}

$* \mathrm{p}<0.05 ; * * \mathrm{p}<0.001$

However youth in the high HIV prevalence community were more sexually experienced (18.4\% vs. $12.1 \%$; $\mathrm{p}<0.001)$ and were more likely to be out of school $(15.1 \%$ vs. $9.2 \%$; $<<0.001)$.

\section{Overall barriers to accessing SRH services}

Perceived barriers for each of the three services are shown in Table 2. "Being embarrassed or shy" was the most commonly reported barrier to seek HIV/STI testing (43\%), and contraceptive services (37\%). "Afraid family would find out", "afraid friends would find out", and "afraid others would find out" were also commonly reported barriers for HIV/STI testing. Afraid for safety was a highly reported barrier for abortion (41\%) and contraception (16.8\%). "Cost/too expensive" was a commonly mentioned barrier for abortion (20.1\%) and contraceptives $(11.8 \%)$ but not for HIV/STI testing.

\section{Differences in barriers by SRH service being sought}

There were significant differences in barriers when assessed by the service being sought (Table 3 ). "Afraid family would find out", "afraid friends would find out", and "afraid others would find out" were significantly greater barriers for HIV/STI testing and abortion when compared with contraception $(p<0.000)$. "Being embarrassed or shy" was a significantly greater barrier for HIV/STI testing and contraception when compared with abortion $(\mathrm{p}<0.000)$. "Afraid for Safety" and "cost" were both significantly more reported as barriers for abortion and contraception compared with HIV testing $(\mathrm{p}<0.000)$. "Religious prohibition" was reported as a significant barrier to seeking abortion services compared with contraception and HIV/STI testing $(\mathrm{p}<0.000)$.

Differences in barriers by SRH service across gender, community, school status and age group

\section{HIV/STI testing}

As shown in Table 4, boys reported "religious prohibition" as a barrier to HIV testing significantly more than girls. Participants in the low HIV prevalence community were more likely to report being "afraid others would find out" (21.6\% vs. $16.4 \%$; $\mathrm{p}<0.05)$ as a barrier to HIV/STI testing than those in the high HIV prevalence community. There were no significant differences in barriers to HIV/STI testing services between inschool and out-of-school youth. A significantly greater per cent of those in the 17-24 age group compared with the 11-16 age group reported "Afraid others might find out" $(22.3 \%$ vs. $16 \%$ $\mathrm{p}<0.05)$, "cost/too expensive" (8.3\% vs. $5.2 \%$, $\mathrm{p}<0.05)$ and "afraid of safety" $(13.8 \%$ vs. $9.6 \%$, $\mathrm{p}<0.05)$ as barriers for HIV/STI testing.

\section{Abortion}

There were no gender differences between reported barriers to abortion. When comparing between the high HIV and low HIV prevalence communities "religious prohibition" 
Table 4: Percent of Respondents Reporting Perceived Barriers to HIV Testing, Abortion, and Contraception by Gender, Age, Community and School Status

\begin{tabular}{lllllllllll}
\hline $\begin{array}{l}\text { Perceived } \\
\text { Barrier }\end{array}$ & & Boys & Girls & $\begin{array}{l}\mathbf{1 1 - 1 6} \\
\text { yrs }\end{array}$ & $\begin{array}{l}\mathbf{1 7 - 2 4} \\
\text { yrs }\end{array}$ & $\begin{array}{l}\text { Low } \\
\text { HIV }\end{array}$ & $\begin{array}{l}\text { High } \\
\text { HIV }\end{array}$ & $\begin{array}{l}\text { Out } \\
\text { School }\end{array}$ & $\begin{array}{l}\text { In } \\
\text { School }\end{array}$ \\
\hline Afraid of & HIV & 14.3 & 15.9 & 13.2 & 17.5 & 15.9 & 14.6 & 14.3 & 15.4 \\
Family & Abortion & 18 & 16.9 & 14.4 & $20.0^{*}$ & 15.7 & 19 & $21.9^{*}$ & 15 \\
Finding Out & Contracept. & 5.5 & $9.6^{* *}$ & 8.8 & 6.9 & 7.3 & 8.2 & 7 & 7.9 \\
Afraid of & HIV & 15.8 & 15.7 & 13.2 & 18.6 & 14.7 & 16.8 & 15.3 & 15.8 \\
Friends & Abortion & 10.3 & 11.4 & 9 & 12.6 & 9.3 & 12.5 & 11.9 & 9.9 \\
Finding Out & Contracept. & 3.6 & $6.7^{*}$ & 5.4 & 5.2 & 3.7 & $6.9 *$ & 4.4 & 5.4 \\
Afraid of & HIV & 18.9 & 19 & 16 & $22.3^{*}$ & $21.6^{*}$ & 16.4 & $22.3^{*}$ & 18 \\
Others & Abortion & 9.6 & 10 & 8.6 & 10.9 & 9.3 & 10.3 & 11.5 & 9 \\
Finding Out & Contracept. & 5.5 & 5.3 & 4.4 & 6.1 & 5.2 & 5.6 & 5.9 & 5.1 \\
Religious & HIV & $1.1 *$ & 0.2 & 0.3 & 0.9 & 0.7 & 0.5 & 0.7 & 0.6 \\
Prohibition & Abortion & 12 & 10.4 & 10.6 & 11.5 & 8.2 & $13.9 * *$ & 13.7 & 10.1 \\
& Contracept. & 2.4 & 3.7 & 2.5 & 3.7 & 2.6 & 3.7 & 3 & 3.1 \\
Embarrassed & HIV & 44 & 43.7 & 41.4 & 46.6 & 42.7 & 44.9 & 45.3 & 43.5 \\
or Shy & & & & & & & & & \\
& Abortion & 28.8 & 29.4 & 26.3 & 31.6 & 30.5 & 27.9 & 28.9 & 29.1 \\
& Contracept. & 37.5 & 37.8 & 36 & 39 & 40.4 & 35 & 36.2 & 37.7 \\
Cost & HIV & 6.9 & 6.4 & 5.2 & $8.3 *$ & 7.9 & 5.4 & 8 & 6.6 \\
& Abortion & 18.4 & 21.4 & 13.9 & $25.5 * *$ & 14.6 & $25.3 * *$ & 22.6 & 18.6 \\
Afraid & Contracept. & 12.9 & 11 & 9.1 & $14 *$ & 10.4 & 13.3 & 14.8 & 10.8 \\
Safety & HIV & 10.3 & 12.6 & 9.6 & $13.8^{*}$ & 10.6 & 12.4 & 14 & 10.8 \\
& Abortion & 42.5 & 41.4 & 39.3 & 44.1 & 43.7 & 40.1 & 46.3 & 40.3 \\
\hline & Contracept. & 14.1 & $19.2^{*}$ & 16.7 & 17.1 & 17.7 & 16.1 & 15.9 & 17.5 \\
\hline
\end{tabular}

$* \mathrm{p}<0.05 ; * * \mathrm{p}<0.001$

$(13.9 \%$ vs. $8.2 \% ;$ p $<0.05)$, "cost/too expensive" $(25.3 \%$ vs. $14.6 \%$; $<0.001)$, and "afraid for safety" $\quad(7.2 \%$ vs. $1.0 \% ; \quad \mathrm{p}<0.001)$ were significantly more reported among youth in the high HIV prevalence community. Significantly more out-of-school youth reported "afraid of family finding out" as a barrier to abortion compared with in-school youth $(21.9 \%$ vs. $15.0 \%$; $\mathrm{p}<0.05)$. Twenty five per cent of youth ages $17-24$ reported cost as a barrier to abortion compared with only $14 \%$ of those in the younger cohort.

\section{Contraception}

There were significant differences for contraceptive services between girls and boys. Girls were significantly more likely than boys to report being "afraid of family finding out" $(9.6 \%$ vs. $5.5 \% ; \mathrm{p}<0.05)$ or "afraid of friends finding out" $(6.67 \%$ vs. $3.58 \%$; p <0.05) as barriers to contraception. Girls were also more likely to report "Afraid for safety" for contraceptive use than boys $(19.22 \%$ vs. $14.08 ; \mathrm{p}<0.05)$. There were no significant differences in barriers to seeking contraception between in-school and out- of-school youth. Those in the high HIV prevalence community reported "afraid of friends finding out" as a barrier to seeking contraception significantly more than those in the low HIV prevalence community $(6.9 \%$ vs. $3.7 \%$ p $<0.05)$. Significantly more youth ages 17-24 reported cost as a barrier to contraceptive services compared with those ages $11-16$ (14.0\% vs. $9.1 \%$; $p<0.05)$.

\section{Discussion}

Results of this analysis identified barriers for seeking three reproductive health services most commonly accessed by youth: HIV/STI testing, abortion and contraception. Being embarrassed was the most commonly reported barrier, which is consistent with previous reports ${ }^{10,30}$. Further assessment about how barriers differed between HIV/STI testing, abortion, and contraception revealed unexpected differences. Barriers to HIV/STI testing and contraception centred on individual shame and stigma around the service (i.e. being embarrassed or having family or friends finding out). Stigma around HIV/STI testing is consistent with other research ${ }^{10,30,31}$, but individual 
stigma around contraception as a more significant barrier for seeking contraception compared with abortion has not been previously documented. One explanation might be that contraception still requires accessing services as part of the formal health system which includes interacting with providers and facing potential discrimination or judgment. Abortion, however is often sought in secret with no link to the formal health system making the service much less public. In addition, contraception is a preventive measure and may be perceived as optional whereas abortion services are curative and may be perceived as necessary or in the case of adolescents, even emergency. Given that contraception is a primary way to prevent unplanned pregnancy and therefore subsequent abortion, additional research to understand this relationship is critical. Barriers around abortion included external perceptions such as fear of family or friends finding out or religion, or structural issues such as cost, which has been reported before ${ }^{16}$. Voucher programs that subsidize the cost of SRH services have been effective in increasing contraceptive access among young people $^{32,33}$ but research around vouchers for safe abortion services has not been documented.

Gender differences existed only for barriers to contraception. In most settings, girls are the primary ones seeking contraceptives (other than condoms) and the stigma associated with premarital sex often affects girls disproportionately. Aside from condoms, the contraceptives most commonly available for youth are hormonal (oral contraceptive pills and injectables) and potential side effects from these affect women more than men. Expanding the method mix to non-hormonal methods such as barrier and/or fertility awareness methods and improved counselling may help alleviate concerns about side effects.

The stigma around HIV/STI or fear of others finding out was significantly greater in the low HIV prevalence community compared with high HIV prevalence community. Youth in the high HIV prevalence community may have been more familiar with HIV/STIs as a more common condition, which may explain why some of these differences existed around HIV/STI stigma. They were also more sexually experienced which may also explain why cost and safety around abortion may have been more significant. Despite sexual experience, the fear of others finding out about contraceptive use was also higher in the high HIV prevalence group indicating a stigma for seeking contraceptives services even in communities where sexual activity is high.

Those in the older age group reported access barriers like cost or safety for HIV/STI testing more than those in the younger group. Cost was also a significantly reported barrier for both abortion and contraception among the older youth. Older youth were also more sexually active with over half (56.9\%) reported ever having sex at the time of the survey so it is expected that they would have a greater need for and therefore more perceived barriers to accessing SRH services.

Recent behavioural research has introduced the concept of behavioural attributes to further understand behaviour change efforts. Behavioural attributes are defined as the unique characteristics that encompass a behavioural domain ${ }^{21}$. These attributes include assessing factors such as the public or private nature of the behaviour or the cost/benefit of the behaviour ${ }^{22}$. Condom use, contraception, and HIV/STI testing vary in their potential behavioural attributes and some of this may have been reflected in this data. HIV/STI testing and seeking contraception is perceived as more public than abortion services which are often done in secret. This may be why the individual stigma or embarrassment around abortion was less than HIV/STI testing or contraception. In comparison, abortion and contraception are associated with factors like cost and religion, which may influence perceptions. These are less seen with regards to HIV/STI testing which is often free. Exploring how these behaviour attributes may influence behaviour change outcomes may be an area for further research.

\section{Limitations}

There were several limitations to this study. First, questions were about perceived barriers and not actual reported barriers. Thus, these results may not reflect the true range of barriers youth face when seeking services. For example few youth in this sample reported provider bias or mistreatment 
however previous research has indicated mistreatment of staff as a key barrier ${ }^{31}$. Second, some of the codes used in the survey instrument may have been difficult to understand. We used cognitive interviewing techniques to pre-test and pilot the survey, but some responses such as "afraid for safety" may have been interpreted differently. For example, some may have understood fear of safety as physical safety when walking or going to a clinic, whereas others may have interpreted fear of safety as fear of medication or procedures. Finally, the sample was a selected group of young people from periurban areas in Ghana and the majority were inschool $(74.5 \%)$. This may not be representative of the majority of youth in Ghana in need of SRH services.

\section{Conclusion}

Interventions to address barriers to SRH services among youth must be multifaceted to address the diversity of youth and the complex way barriers differ depending on the service being sought. Embarrassment and individual stigma associated with SRH services especially HIV/STI testing still exists across services. However, when compared with each other, embarrassment was more commonly reported as a perceived barrier to contraception than to abortion possibly reflecting a greater individual stigma around contraception than abortion services. Given that contraception is a primary method to prevent unplanned pregnancy and resulting abortion, social and behaviour change interventions to change attitudes, beliefs and norms around the use of contraceptives for youth, parents, and providers are important. Cost and safety were reported as significant barriers when seeking abortion and to lesser degree contraceptives, so interventions such as vouchers to reduce or mitigate the cost and efforts ensure the safety of such services may also be warranted.

With the country's demographic age structure changing and an increasingly larger youth population, Ghana is well positioned to capitalize on the demographic dividend. However, this will require investments in improved sexual and reproductive health services especially among younger populations. This will not only enable improved health outcomes, but may also foster increased access to education and economic opportunities for youth in Ghana ${ }^{6,7}$.

\section{Acknowledgements}

This research was supported with funding from the Eunice Kennedy Shriver National Institute for Child Health and Human Development (R01HD061017). The findings and conclusions of this paper are those of the authors and do not necessarily represent the official position of the National Institutes of Health.

\section{Contribution of Authors}

NT conceived and designed the study with input from JBB. NT and JBB conducted the data collection. NT analysed the data and led the manuscript writing. $\mathrm{KN}$ and RNR provided technical input and guidance on the context and analysis. All authors contributed to and reviewed the manuscript.

\section{References}

1. UNAIDS. UNAIDS Report on the Global AIDS Epidemic. Geneva: 2010.

2. Dehne Karl L, Reidner Gabrielle. Sexually Transmitted Infections among Adolescents: The need for adequate health services. Geneva: WHO; 2005.

3. Blum Robert W. Youth in sub-Saharan Africa. J Adolesc Health Off Publ Soc Adolesc Med 2007;41(3):230 8. Doi: 10.1016/j.jadohealth.2007.04.005.

4. Godia Pamela M, Olenja Joyce M, Hofman Jan J, van den Broek Nynke. Young people's perception of sexual and reproductive health services in Kenya. BMC Health Serv Res 2014;14:172. Doi: 10.1186/1472-6963-14-172.

5. Kerry MacQuarrie. Unmet Need for Family Planning among Young Women: Levels and Trends. Rockville Maryland USA: ICF Macro International; 2014.

6. Drummond Paulo, Thakoor Vimal J, Yu Shu. Africa rising: harnessing the demographic dividend 2014.

7. Ghana Statistical Service (GSS), Ghana Health Service (GHS). 2010 Population and housing report: Children, adolescents and young people in Ghana. Accra, Ghana: 2013.

8. Patton GC, Coffey C, Cappa C, Currie D, Riley L, Gore $\mathrm{F}$, et al. Health of the world's adolescents: a synthesis of internationally comparable data. The Lancet 2012.

9. Guttemacher Institute. Adolescents in Ghana: Sexual and Reproductive Health. New York, New York: 2004.

10. Biddlecom AE, Munthali A, Singh S, Woog V. 
Adolescents' views of and preferences for sexual and reproductive health services in Burkina Faso, Ghana, Malawi and Uganda. Afr J Reprod Health 2007;11(3):99.

11. Esantsi SF, Onyango F, Quansah Asare GJ, Kuffour EO, Tapsoba P, Birungi $\mathrm{H}$, et al. Understanding the Reproductive Health Needs of Adolescents in Selected Slums in Ghana: A Public Health Assessment. Population Council; 2015.

12. Guttemacher Institute. Abortion in Ghana. 2013.

13. Mbeba Rita Moses, Mkuye Martin Sem, Magembe Grace Elias, Yotham William Lubazi, obeidy Mellah Alfred, Mkuwa Serafina Baptist. Barriers to sexual reproductive health services and rights among young people in Mtwara district, Tanzania: a qualitative study. Pan Afr Med J 2012;13(Supp 1).

14. Chandra-Mouli Venkatraman, McCarraher Donna R, Phillips Sharon J, Williamson Nancy E, Hainsworth Gwyn. Contraception for adolescents in low and middle income countries: needs, barriers, and access. Reprod Health 2014;11(1):1-8.

15. Sidze Estelle M, Lardoux Solene, Speizer Ilene S, Faye Cheikh M, Mutua Michael M, Badji Fanding. Young women's access to and use of contraceptives: the role of providers' restrictions in urban Senegal. Int Perspect Sex Reprod Health 2014;40(4):176-83. Doi: 10.1363/4017614.

16. Henry R, Fayorsey C. Coping with Pregnancy: Experiences of Adolescents in Ga Mashi, Accra. Calverton MD: ORC Macro; 2002.

17. Olugbenga-Bello Adenike I, Adebimpe Wasiu O, Akande Roseline O, Oke Olufemi S. Health risk behaviors and sexual initiation among in-school adolescents in rural communities in southwestern Nigeria. Int J Adolesc Med Health 2014. Doi: 10.1515/ijamh-2013-0326.

18. Bruce Dick, Jane Ferguson, Venkatrman Chandra-Mouli, Loretta Brabin, Siubidita Chatterjee, David A. Ross. Review of the evidence for interventions to increase young people's use of health services in developing countries," in David A. Ross, Bruce Dick, and Jane Ferguson (eds.), Preventing HIV/AIDS in Young People: A Systematic Review of the Evidence from Developing Countries. Geneva: WHO, pp. 151-204. 2006.

19. Zuurmond Maria A, Geary Rebecca S, Ross David A. The effectiveness of youth centers in increasing use of sexual and reproductive health services: a systematic review.Stud Fam Plann 2012;43(4):23954. Doi: 10.1111/j.1728-4465. 2012.00324.x.

20. Chandra-Mouli Venkatraman, Lane Catherine, Wong Sylvia. What Does Not Work in Adolescent Sexual and Reproductive Health: A Review of Evidence on Interventions Commonly Accepted as Best Practices. Glob Health Sci Pract 2015;3(3):333-40. Doi: 10.9745/GHSP-D-15-00126.

21. Lapinski Maria Knight, Rimal Rajiv N, Devries Rebecca, Lee Ee Lin. The role of group orientation and descriptive norms on water conservation attitudes and behaviors. Health Commun 2007;22(2):133-42. Doi: 10.1080/10410230701454049.

22. N Rimal Rajiv, Lapinkski Maria Knight, Turner Monique Mitchell, Smith Katherine Clegg. The attribute-centered approach for understanding health behaviors: Initial ideas and future research directions. J Swiss Assoc Commun Media Res 2011;11(1):15-34.

23. Deribe Kebede, Woldemichael Kifle, Njau Bernard Joseph, Yakob Bereket, Biadgilign Sibhatu, Amberbir Alemayehu. Gender differences regarding barriers and motivators of HIV status disclosure among HIV-positive service users. SAHARA J J Soc Asp HIVAIDS Res Alliance SAHARA Hum Sci Res Counc 2010;7(1):30-9.

24. Kirby Douglas. The impact of schools and school programs upon adolescent sexual behavior. J Sex Res 2002;39(1). Doi: 10.1080/00224490209552116.

25. Speizer Ilene S, Fotso Jean Christophe, Davis Joshua T, Saad Abdulmumin, Otai Jane. Timing and circumstances of first sex among female and male youth from select urban areas of Nigeria, Kenya, and Senegal. J Adolesc Health Off Publ Soc Adolesc Med 2013;53(5):609-16. Doi: 10.1016/ j.jadohealth.2013.06.004.

26. WHO. Expanding access to contraceptive services for adolescents. 2012.

27. National Population Council. Ghana Adolescent Reproductive Health Policy. 2001.

28. Ghana AIDS Commission. Country AIDS Response Progress Report. Accra: Ghana AIDS Commission; 2014.

29. Bingenheimer Jeffrey B, Reed Elizabeth. Risk for coerced sex among female youth in Ghana: roles of family context, school enrollment and relationship experience. Int Perspect Sex Reprod Health 2014;40(4):184-95. Doi: 10.1363/4018414.

30. Oppong-Odiseng AC, Heycock EG. Adolescent health services--through their eyes. Arch Dis Child 1997;77(2):115-9.

31. Strauss Michael, Rhodes Bruce, George Gavin. A qualitative analysis of the barriers and facilitators of HIV counselling and testing perceived by adolescents in South Africa. BMC Health Serv Res 2015;15. Doi: 10.1186/s12913-015-0922-0.

32. Meuwissen Liesbeth E, Gorter Anna C, Knottnerus Andre JA. Impact of accessible sexual and reproductive health care on poor and underserved adolescents in Managua, Nicaragua: a quasiexperimental intervention study. J Adolesc Health Off Publ Soc Adolesc Med 2006;38(1). Doi: 10.1016/j.jadohealth.2005.01.009.

33. Eva Gillian, Quinn Andrew, Ngo Thoai D. Vouchers for family planning and sexual and reproductive health services: A review of voucher programs involving Marie Stopes International among 11 Asian and African countries. Int J Gynaecol Obstet Off Organ Int Fed Gynaecol Obstet 2015;130 Suppl 3. Doi: 10.1016/j.ijgo.2015.06.023. 